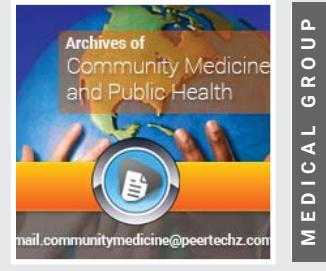

\title{
Pesticide exposure and ocular toxicity
}

\section{Joseph Laquatra*}

Ph.D, Professor Emeritus, Department of Design and Environmental Analysis, Cornell University, Ithaca, NY, USA

\author{
Received: 17 February, 2020 \\ Accepted: 06 April, 2020 \\ Published: 07 April, 2020
}

*Corresponding author: Joseph Laquatra, Ph.D, Professor Emeritus, Department of Design and Environmental Analysis, Cornell University, Ithaca, NY, USA, E-mail: JL27@cornell.edu

Keywords: Pesticide residues; Child breathing zone; Ocular toxicity

https://www.peertechz.com

\section{Abstract}

Pesticide residues accumulate in homes with higher amounts that are found in the Child Breathing Zone. Negative health effects are known to exist from exposure to pesticide residues, including ocular toxicity. This paper reports on a study of pesticide residues found in a random sample of 132 homes in non-metropolitan counties of New York State. Fifteen pesticides were tested for and residues from all fifteen pesticides were found in all 132 homes. Potential consequences of human exposure to these residues are discussed as is a potential remedy.

\section{Introduction}

Pesticide residues are ubiquitous in home environments [1]. A wide range of adverse human health impacts can occur through exposure to these residues including cancer, birth defects, leukemia, and ocular toxicity [2]. For physiological and behavioral reasons, children are at a higher risk than adults for both exposure to environmental toxicants and for adverse health effects from those toxicants [3]. Children are more highly exposed to environmental pollutants than adults because they breathe more air per pound of body weight and chew or suck on toys and hands that have been in contact with pollutants [4].

Babies crawl on the floor and young children walk, run, and play on the floor; thus, the breathing zone of children is much lower (up to $1 \mathrm{~m}$ from the floor). This zone is known as the Child Breathing Zone (CBZ). Resuspension of respirable particulates, including pesticide residues, is caused by walking-induced turbulence in a room, and shorter people are exposed to more resuspended particulates than taller people. Tripathii and Laquatra [5] showed that indoor air quality can be significantly worse in the CBZ than in the Adult Breathing Zone (ABZ), and the assumption of uniform pollutant concentration in indoor environments can be an erroneous assumption of breathing concentration risk. Although there is an increasing awareness that children are vulnerable to poor IAQ in the scientific community there is very limited research with a focus on IAQ in the CBZ. There is no current IAQ management system that specifically focuses on improving IAQ in the CBZ.

Exposure to pesticides poses health risks to humans, especially infants and children [6]. Babayigit, Tekbas, and Cetin [7] reported that these risks include cancer, birth defects, nervous system disorders, and endocrine system disorders. Obendorf, et al. [8] listed adverse health effects from exposure to organophosphate pesticides and carbamates as depressed cholinesterase in red blood cells and death at high enough exposure levels. Jaga and Dahrmani [2] described pesticiderelated damage to eyes. Ocular toxicity results from exposure routes that include ocular and oral exposure and dermal contact. Toxic effects include irritation, blurry vision, burning feelings, and eye watering. Toxicity affects the cornea, retina, lens, conjunctiva, and optic nerve.

Studies of pesticide residues in homes have documented entry routes that include tracking with shoes, bare feet, clothing, or animal fur; airborne entry; and soil gas entry $[9,10]$. Adjacency and proximity to agricultural operations have also been cited as factors responsible for residential pesticide residues because of spray drift and volatility [11]. Lawn-applied pesticides can follow these same transport routes [10]. Once inside a home, pesticide residues accumulate in dust and degrade at a lower rate than they do outdoors because they are shielded from the effects of rain, sun, and soil microbial activity [12]. 


\section{Methods}

To examine the extent of indoor pesticide pollution in rural homes, pesticide sampling and analyses were conducted as part of a larger effort that studied pollutants in homes and childcare facilities [13]. Fifteen pesticides with a likelihood of accumulation in the interiors of rural homes were selected for this study. Researchers involved with this study received approval to proceed from the Cornell University Institutional Review Board.

A two-stage random sampling procedure was used to obtain a representative sample of households in all non-metropolitan counties in New York State. A hierarchical cluster analysis using average linkage methods [14] was performed on the twentyfour non-metropolitan counties in the state. The analysis was conducted in order to determine similar groupings of counties to be used as categories in a stratified sampling design. The counties were grouped based on five housing characteristics: average number of persons per household, proportion of housing units in multiple family dwellings, proportion of housing units occupied by renters, proportion of housing units built before 1979, and proportion of housing units built after 1980. The cluster analysis resulted in six groupings of counties When one county was randomly selected from each group, the resulting selection comprised Chenango, Columbia, Essex, Franklin, Wyoming, and Hamilton counties.

Budget constraints limited the sample size to approximately 350 homes. Weighted random sampling based on population was conducted in each county. The final sample size was $n=328$. Each household in this sample was given the opportunity to have pollutant tests conducted; and 132 households agreed to this.

A technician visited the 132 houses to conduct these tests during the heating season of $2000-2001$, and two wipe samples were collected from each participant home. One sample was taken from a carpeted floor area and one from a non-carpeted ("smooth-floor") area. When possible sample areas were selected from main living/traffic areas of the home (living, dining, family room, main entrance hall). The pesticides were selected based on those commonly used in agricultural practices in the counties that were studied.

Laquatra, et al. [5] described the pesticide extraction and identification procedures used in this analysis. Methods differed for acid and non-acid pesticides. The non-acid pesticides were extracted from dust with ethyl acetate:cyclohexane (3:1) which was replaced with dichloromethane. The extract was filtered and collected with Size Exclusion Chromatography (SEC) using a high-resolution SEC polyvinyl benzene/polystyrene column (EnvirosepABC column) protected by an EnvirosepABC guard column (Phenomenex, Torrance, CA) on a HP1090 HPLC (Agilent Technologies, Sunnyvale, CA) equipped with diode array detector (DAD). Hong, et al. [15] present detailed SEC conditions. The effluent was manually collected and condensed for GC/MS analysis. Acetone was used to extract filter paper samples for GC/MSD analysis. Pesticides were analyzed on a HP5890 Series II gas chromatograph coupled to a HP 5971A MS (Agilent Technologies, Sunnyvale, CA). Hong, et al. [15] detail the operating conditions. Characteristic MS fragment ions and chromatographic retention times were used to identify pesticides by matching. Quality assurance methods described by Hong, et al. [15] were followed.

Acid pesticides were taken out of dust with distilled water and calcium hydroxide. PH was adjusted (1 to 2 ) and effluent cleaned by solid phase extraction with a polyvinyl benzene/ polystyrene cartridge. The cartridge was washed with distilled water at pH 2 and eluted with methanol in MTBE. The solution was extracted with diethyl ether. The extract was dried, followed by addition of methanol and trimethylsilyl diazomethane to methylate the carboxylic acid pesticides.

Acidified acetone ( $3 \mathrm{mM} \mathrm{H} \mathrm{HO}_{4}$ ) was extracted with filter paper samples. The extract was condensed, methylated, and injected into the GC in the same way as dust extract except SPE cleanup was not used. Optimized GC/MS conditions were similar to those for non-acid pesticides [15].

Pesticide residue results from the non-carpeted areas are presented in Table 1 . Note that residues of each pesticide tested for were found in every home in the sample.

\section{Discussion}

The fact that pesticide residues were found in every house tested in our sample indicates the ubiquitous nature of these chemicals in the rural environment. Similar findings were also

Table 1: Pesticide residues from non-carpeted areas.

\begin{tabular}{|c|c|c|c|c|}
\hline Pesticide[1] & & Mean & Minimum & Maximum \\
\hline $\mathrm{N}=132$ & & & $\left(\right.$ Results in $\left.\mu \mathrm{g} / \mathrm{m}^{2}\right)$ & \\
\hline Chlorpyrifos & (NA) & 0.00641565 & 0.000027 & 0.035563 \\
\hline Methamidophos & (NA) & 0.01534285 & 0.000022 & 0.091044 \\
\hline Malathion & (NA) & 0.02316181 & 0.000019 & 0.595709 \\
\hline Picloram Acid & (A) & 0.02505954 & 0.000522 & 0.983467 \\
\hline Methyl Parathion & (NA) & 0.00119004 & 0.000026 & 0.044459 \\
\hline Atrazine & (NA) & 0.00081807 & 0.000029 & 0.040208 \\
\hline Diazinon & (NA) & 0.00715122 & 0.00002 & 0.077364 \\
\hline Carbaryl & (NA) & 0.00305338 & 0.00003 & 0.185368 \\
\hline Prowl & (NA) & 0.01606887 & 0.000026 & 0.147364 \\
\hline Resmethrin & (NA) & 0.00056852 & 0.000025 & 0.01974 \\
\hline Tetramethrin & (NA) & 0.01515323 & 0.000029 & 0.086751 \\
\hline Alachlor & (NA) & 0.00798413 & 0.000003 & 0.049125 \\
\hline Trifluralin & (NA) & 0.00209427 & 0.000017 & 0.043156 \\
\hline Metolachlor & (NA) & 0.01935394 & 0.000028 & 0.136299 \\
\hline 2,4D-acid & (A) & 0.00853624 & 0.00035 & 0.226174 \\
\hline & & & \\
\hline
\end{tabular}

${ }^{1}$ The type of pesticide is indicated in parentheses. $A=$ acid; $N A=$ non-acid. 
reported by Obendorf, et al. [8], Smith, et.al. [16], and Starr, et al. [17].

This study showed residues of five organophosphate pesticides in homes: Chlorpyrifos, Methamidophos, Malathion, Methyl Parathion, and Diazinon. This class of pesticides was reviewed by Jaga and Dahrmani [2] for ocular toxicity. Negative consequences from exposure include conjunctivitis and ocular hyperemia. Other health effects include retinal degeneration optic neuropathy, retinopathy, ocular motor palsy, and cataracts.

Regarding the other pesticide residues observed, Picloram Acid is classified by the U.S. Environmental Protection Agency (EPA) as a Restricted Use Pesticide that has been shown to be of moderate to low acute toxicity [18]. Atrazine has been shown to cause reproductive problems [19]. Human exposure to large amounts of carbaryl can be toxic to nervous and respiratory systems [20]. Prowl is classified by the EPA as a possible human carcinogen [21]. Pyrethroids are associated with nervous system damage [22]. Alachlor has the potential to cause cancer in laboratory animals [23]. Trifluralin can cause allergic dermatitis from prolonged exposure [24]. Metolachlor is slightly toxic if ingested [25]. 2,4D-acid may cause birth defects at high doses [26].

McCaule, et al. [27] reported that residential cleaning practices can significantly reduce pesticide residues, but those practices are specific to different surfaces. This indicates that educators involved in pesticide education programs may want to include program elements that include home maintenance guidelines for prevention of and safe eradication of accumulated pesticide residues of which consumers may not be aware. This could be an important component of public health education efforts.

\section{References}

1. Laquatra J, Pierce M, Hedge A, Lemley A (2018) Common pesticide residues in rural homes of New York State. JSM Health Education \& Primary Health Care 3: 1042-1045.

2. Jaga K, Dharmani C (2006) Ocular toxicity from pesticide exposure: A recent review. Environmental Health and Preventive Medicine 11: 102-107. Link: https://bit.ly/2XfaiSg

3. Canha N, Mandin C, Ramalho O, Wyart G, Ribéron J, et al. (2016) Assessment of ventilation and indoor air pollutants in nursery and elementary schools in France. Indoor Air 26: 350-365. Link: https://bit.ly/2wkttPn

4. Klepeis NE, Nelson WC, Ott WR, Robinson JP, Tsang AM, et al. (2001) The National Human Activity Pattern Survey (NHAPS): A resource for assessing exposure to environmental pollutants. J Exposure Analysis Environmental Epidemiology 1: 231-252. Link: https://bit.ly/3dV8uUp

5. Tripathii, E. and Laquatra, J. (2018). Managing indoor air quality in the child breathing zone: risk analysis and mitigation, Journal of Architectural Engineering 24. Link: https://bit.ly/3916gV2

6. Thompson B, Griffith WC, Barr DB, Coronado GD, Vigoren EM, et al. (2014) Variability in the take-home pathway: Farmworkers and non-farmworkers and their children. Journal of Exposure Science and Environmental Epidemiology, 24: 522-531. Link: https://go.nature.com/2xSpNEY
7. Babayigit MA, Tekbas OF, Cetin H (2014) Public health effects of pesticides used in pest management and precautions for the protection. TAF Preventive Medicine Bulletin 13: 405-412. Link: https://bit.ly/3e2wEMP

8. Obendorf S, Lemley A, Hedge A, Kline AA, Tan K, et al. (2006) Distribution of pesticide residues within homes in central New York State. Archives of Environmental Contamination and Toxicology, 50: 31-44. Link: https://bit.ly/3c8PC2D

9. Lemley AT, Hedge A, Obendorf SK, Hong S, Kim J, et al. (2002) Selected pesticide residues in house dust from farmers' homes in central New York State, USA. Bulletin of Environmental Contamination and Toxicology. 69 : 155-163. Link: https://bit.ly/2Xewko4

10. Nishioka MG, Burkholder HM, Brinkman MC, Gordon SM, Lewis RG (1996) Measuring transport of lawn-applied herbicide acids from turf to $\mathrm{h} 0 \mathrm{~m} \mathrm{e}$ : correlation of dislodgeable 2,4-D turf residues with carpet dust and carpet surface residues. Environmental Science and Technology 30: 3313-3320. Link: https://bit.ly/2wgObj4

11. Nishioka MG, Lewis RG, Brinkman MC, Burkholder HM., Hines CE, et al (2001) Distribution of 2,4-D in air and on surfaces inside residences after lawn applications: comparing exposure estimates from various media for young children. Environmental Health Perspectives 109: 1185-1191. Link: https://bit.ly/2JIZFPo

12. Simcox NJ, Fenske RA, Wolz SA, Lee I, Kalman DA (1995) Pesticides in household dust and soil: exposure pathways for children. Environmental Health Perspectives 103: 1126-1134. Link: https://bit.ly/2Xc7BAR

13. Laquatra J, Maxwell LE, Pierce M (2005) Indoor air pollutants: limited-resource households and child care facilities. Journal of Environmental Health 67: 3943. Link: https://bit.ly/39Qzdhz

14. Johnson RA, Wichern DW (2002) Applied Multivariate Statistical Analysis, $5^{\text {th }}$ ed. Upper Saddle River, NJ: Prentice Hall. Link: https://bit.ly/3dV8uUp

15. Hong S, Kim J, Lemley AT, Obendorf SK, Hedge A (2000) Analytical method development for 18 pesticides in house dust and settled residues using SEC SPE, TMS Methylation, and GCMS. J Chromatographic Science 39: 101-112. Link: https://bit.ly/2V6t9fz

16. Smith MN, Workman T, Mcdonald KM, Vredevoogd MA, Vigoren EM, et al. (2017) Seasonal and occupational trends of five organophosphate pesticides in house dust. Journal of Exposure Science and Environmental Epidemiology 27: 372-378. Link: https://bit.ly/3e0L0x7

17. Starr J, Graham S, Stout II D, Andrews K, Nishioka M (2008) Pyrethroid pesticides and their metabolites in vacuum cleaner dust collected from homes and day-care centers. Environmental Research 108: 271-279. Link: https://bit.ly/34hicfe

18. U.S. Environmental Protection Agency (EPA) (1995) R.E.D. Facts: Picloram EPA-738-F-95-018. Link: https://bit.ly/3e3uYIU

19. Agency for Toxic Substances \& Disease Registry (2003) Public health statement for Atrazine. Link: https://bit.ly/3e0m3BM

20. Extension Toxicology Network (1993). Pesticide Information Profile: Carbaryl. Link: https://bit.ly/2JMLIp7

21. U.S. Environmental Protection Agency (EPA) Office of Pesticide Programs, Health Effects Division, Science Information Management Branch. Chemicals Evaluated for Carcinogenic Potential USEPA Office of Pesticide Programs, Health Effects Division, Science Information Management Branch (2006). Chemicals Evaluated for Carcinogenic Potential.

22. Agency for Toxic Substances \& Disease Registry (2003b) Public health statement for Pyrethrins and Pyrethroids. Link: https://bit.ly/39STUJz

23. Extension Toxicology Network (1996). Pesticide Information Profile: Alachlor Link: https://bit.ly/2XevOGE 
24. Extension Toxicology Network (1996c) Pesticide Information Profile: Trifluralin. Link: https://bit.ly/3aOLqEX

25. Extension Toxicology Network (1996b) Pesticide Information Profile: Metolachlor. Link: https://bit.ly/3bWNU3Z
26. Extension Toxicology Network (1996d) Pesticide Information Profile: 2: 4-D. Link: https://bit.ly/3aSnmRA

27. McCaule RA, Travers R, Lasarev M, Muniz J, Nailon R (2006) Effectiveness of cleaning practices in removing pesticides from home environments. $J$ Agromedicine 11: 81-88. Link: https://bit.ly/2JHgx9v

\section{Discover a bigger Impact and Visibility of your article publication with}

Peertechz Publications

\section{Highlights}

* Signatory publisher of ORCID

* Signatory Publisher of DORA (San Francisco Declaration on Research Assessment)

* Articles archived in worlds' renowned service providers such as Portico, CNKI, AGRIS, TDNet, Base (Bielefeld University Library), CrossRef, Scilit, J-Gate etc.

* Journals indexed in ICMJE, SHERPA/ROMEO, Google Scholar etc.

* OAI-PMH (Open Archives Initiative Protocol for Metadata Harvesting)

* Dedicated Editorial Board for every journa

* Accurate and rapid peer-review process

* Increased citations of published articles through promotions

* Reduced timeline for article publication

Submit your articles and experience a new surge in publication services (https://www.peertechz.com/submission).

Peertechz journals wishes everlasting success in your every endeavours distribution, and reproduction in any medium, provided the original author and source are credited. 